important donors are: the Arab Gulf Programme, Australia, Bangladesh, Belgium, Canada, Denmark, the Ford Foundation, France, Holland, Japan, the Norwegian Agency for International Development, Saudi Arabia, Switzerland, the United Kingdom, Unicef, the United Nations Development Programme, USAID, the World Health Organisation, and the World Bank. We thank Dr A Foster and Dr J Menken for their help and advice in the statistical analysis and Drs $R$ Eeckels, V Fauveau, A Hall, and F Henry (ICDDR,B) for their help and encouragement during the preparation of the manuscript.

1 Anonymous. Growth monitoring: intermediate technology or expensive luxury? [Editorial]. Lancet 1985;ii:1337-8.

2 Morley D. Growth monitoring. In: Grant JP, ed. State of the world's children 1984. Oxford: Oxford University Press, 1983:77-81

Morley D, Woodland M. See how they grow: monitoring child growth for appropriate health care in developing countries. London: McMillan, 1979.

+ World Health Organisation. Guidelines for training community health workers in nutrition. Geneva: WHO, 1981. (Offset publication No 59.)

American Public Health Association. Primary health care issues: growth monitoring. Washington, DC: APHA, 1981.

6 Aga Khan Foundation. Primary health care technologies at the family and community levels. Geneva: Aga Khan Foundation, 1986.

7 World Health Organisation. The growth chart: a tool for use in infant and child care. Geneva: WHO, 1986.

Hebert JR. Growth monitoring: the "G" in GOBI-FFF. In: Cash R, Keusch $\mathrm{G}$, Lamstein J, eds. Child health and survival-the UNICEF GOBI-FFF program. London: Croom Helm, 1987:11-20.

9 International Centre for Diarrhoeal Disease Research, Bangladesh. Annual report 1986. Dhaka: ICDDR,B, 1987

10 National Center for Health Statistics. Growth curves for children, birth-18 years, United States. Vital Health Stat 1977;ser 11:No 165.
11 World Health Organisation Working (iroup. Use and interpretation of anthropometric indicators of nutritional status. Bull WHO 1986;64:929-4l.

12 Armitage P. Statistical methods in medical research. Oxford: Blackwell Scientific, 1971

13 Kleinbaum DG, Kupper LL, Morgenstern H. Epidemiological research: principles und quantitative methods. Belmont, CA: Lifetime Learming Publications, 1982

14 Habicht JP, Meyers LD, Brownie C. Indicators for identifying and counting the improperly nourished. Am f Clin Nutr 1982;35:1242-54.

15 Cogill B. Ranking anthropometric indicators using mortality in rural Bangladeshi children, Ithaca, NY: Cornell University, 1983. (MSC thesis.) 16 Brownie $C$, Habicht JP, Cogill B. Comparing indicators of health and nutritional status. Am 7 Epidemiol 1986;124:1031-44.

17 SAS Institute. SUGI supplemental library user's guide, version 5. Cary, NC: SAS Institute, 1986.

18 Gomez F, Ramos-Galvan R, Frenk F, Cravioto JM, Chavez R, Vasquez J. Mortality in second and third degree malnutrition. $\mathcal{F}$ Trop Pediatr 1956;2 77-83.

19 Bairagi R, Chowdhury MK, Kim YJ, Curlin GT. Alternative indicators of mortality. Am f Clin Nutr 1985;42:296-306.

20 Kasongo Project Team. Growth decelerations among under-5-year-old children in Kasongo (Zaire). II. Relationship with subsequent risk of dying, and operational consequences. Bull WHO 1986;64:703-9.

21 Kasongo Project Team. Growth deceleration among under-5-year-old children in Kasongo (Zaire). I. Occurrence of decelerations and impact of measles on in Kasongo (Zaire). 1. Occurrence of dec

22 Brown KH, Black RE, Becker S, Hoque A. Patterns of physical growth in a longitudinal study of young children in rural Bangladesh. Am f Clin Nutr 1982;36:294-302.

23 Zerfas AJ. Anthropometric field methods: general. In: Jelliffe DB, Jelliffe EFP, eds. Nutrition and growth. New York: Plenum Press, 1979:339-64.

24 Van Loon $H$. Epidemiology of malnutrition in developing countries. Louvrain: Katholieke Universiteit Leuven, 1987. (Thesis.)

25 Briend A, Woityniak B, Rowland MGM. Arm circumference and other factors in children at a high risk of death in rural Bangladesh. Lancet 1987;ii:725-8.

Accepted 7 April 1989)

\title{
Postoperative radiotherapy and late mortality: evidence from the Cancer Research Campaign trial for early breast cancer
}

\author{
J L Haybittle, D Brinkley, J Houghton, R P A'Hern, M Baum
}

Medical Research Council Trials Office, Cambridge CB2 2BW

$\mathrm{J}$ L Haybittle, PHD, honorary statistician

King's College Hospital, London

D Brinkley, FRCs, honorary consultant in radiotherapy and oncology

M Baum, FRCs, professor of surgery

Cancer Research

Campaign Clinical Trials

Centre, Rayne Institute,

London SE5 9NU

J Houghton, BSC, assistant director

R P A'Hern, MSC, statistician

Correspondence to: Mrs Houghton.

BrMed f 1989;298:1611-4
Abstract

Objective-To identify any excess mortality caused by adjuvant radiotherapy for early breast cancer.

Design-Prospective randomised clinical trial. Two thousand subjects needed for study to have a $\mathbf{9 0 \%}$ chance of detecting a difference in survival rate of $7 \%$ with $95 \%$ significance. Patients were followed up until June 1988, giving follow up of 158-216 months.

Setting-A multicentre trial mainly drawing patients from centres in the United Kingdom.

Patients -2800 Women presenting with clinical stage I or II carcinoma of the breast from June 1970 to April 1975.

Interventions-One group of women $(n=1376)$ had simple mastectomy followed by immediate postoperative radiotherapy (1320 to 1510 rets). The remaining women $(n=1424)$ had simple mastectomy with subsequent careful observation of the axilla, radiotherapy being delayed until there was obvious progression or recurrence of disease locally.

End point - Increased mortality in patients treated with radiotherapy from causes other than breast cancer.

Measurements and main results-Survival was measured from time of first treatment to death or last follow up. Deaths from any cause and from specified causes were counted as events. Comparison over the whole follow up showed a slight excess mortality in the group treated with radiotherapy (relative risk $1.04 ; 95 \%$ confidence interval 0.94 to 1.15 ). The relative risk of death from breast cancer was 0.97 $(0.87$ to 1.08$)$ but that of death from other causes was $1.37(1.09$ to 1.72$)$, the increase mainly being in women who had had tumours of the left breast (1.61
$(1 \cdot 17$ to $2 \cdot 24)$ ) and had been treated with orthovoltage (1.85 (1.27 to 2.71$))$. Analysis of causes of death after five years showed a relative risk of $2 \cdot 11$ $(1.25$ to 3.59$)$ for new malignancies and of $1.65(1.05$ to 2.58 ) for cardiac disease, the increase in cardiac mortality being most pronounced in patients who had had tumours of the left breast and whose treatment had included orthovoltage radiation (relative risk $2.67(1.28$ to $5 \cdot 55)$ ).

Conclusions - Adjuvant radiotherapy after simple mastectomy for early breast cancer produces a small excess late mortality from other cancers and cardiac disease. The risk has to be balanced against the higher risk of local recurrence when immediate postoperative radiotherapy is not given. The balance has to be assessed for each patient, and for many patients radiotherapy will still be desirable in the initial treatment of their early breast cancer.

\section{Introduction}

Postoperative radiotherapy reduces the rate of local recurrence after treatment for early breast cancer. ${ }^{2}$ No significant improvement in rates of survival has been shown after radiotherapy, and some critics have claimed that it has a deleterious effect. ${ }^{3}$ Cuzick et al carried out an overview of 10 randomised trials in which the difference between the two groups was solely whether patients had been irradiated postoperatively. ${ }^{+}$ This overview showed no significant effect on survival up to 10 years, but beyond 10 years the mortality in the irradiated patients was signficantly increased. This finding was greatly. influenced by the earlier trials, which contributed most to the long term follow up and tended to use orthovoltage rather than supervoltage radiation. 
The largest trial in Cuzick et al's overview was the Cancer Research Campaign (King's/Cambridge) trial, which compared simple mastectomy and postoperative radiotherapy with simple mastectomy followed by a watch policy. This trial started in 1970 and had a maximum follow up at the time of the overview of 14 years. Of all deaths after 10 years' follow up included in the overview, only one fifth were from the Cancer Research Campaign trial. Nevertheless, Cuzick et al reported that on its own the data showed an increased risk of death in the group treated with radiotherapy after 10 years, the relative risk being $1.50(95 \%$ confidence interval $1 \cdot 07$ to $2 \cdot 11$ ). They also reported a similar trend from five to 10 years with a relative risk of $1 \cdot 21(1.01$ to $1 \cdot 44)$.

If increased late mortality in patients given radiotherapy is a true effect several questions arise concerning the reasons for this. Is it due to late failure of treatment as would be shown by increased deaths from cancer of the breast? Is it due to the carcinogenic effect of radiation causing an increase in deaths from other cancers? Or is it due to other effects of radiation on normal tissues causing late changes in those tissues that precipitate death?

We tried to answer these questions by detailed analysis of the data from the Cancer Research Campaign trial on causes of death in the two groups.

\section{Patients and methods}

The dataset consisted of all randomised patients: 1376 treated by simple mastectomy and postoperative radiotherapy and 1424 treated by simple mastectomy followed by a watch policy. The results at 10 years were reported in 1980 and showed a significant decrease in the rate of local recurrence in the group treated with radiotherapy but no difference in mortality between the two groups. 2 The recommended radiotherapy regimens delivered doses in the range 1320 to 1510 rets. A detailed analysis of the radiotherapy treatments and the sites of local recurrence has been given by Brinkley et al.

Entry into the trial took place from June 1970 to April 1975. We have analysed the data as at 30 June 1988 , when follow up varied from 158 to 216 months. Thus follow up was longer than when analysed by Cuzick et al. ${ }^{+}$

Causes of death were determined from information given on the death report form, copies of death certificates, and, in some cases, correspondence with treating clinicians and examination of the patient's notes. Deaths were first classified as due or not due to breast cancer. Deaths not due to breast cancer were then subdivided into deaths from other malignant disease; deaths related to cardiac disease - that is, heart failure, myocardial infarct, coronary thrombosis; and deaths from all other causes. Included in this last group were all cardiovascular deaths not recorded in the second group. A few patients could not be classified, and for some others there was considerable uncertainty about the correct classification.

Statistical comparisons between the two groups were made with logrank tests, ${ }^{\circ}$ counting as events all deaths or one particular classification of death-for example, deaths due to breast cancer and deaths related to cardiac disease.

\section{Results}

Figure 1 shows the survival curves in the two groups over the 18 years of follow up. Mortality was slightly higher in the group treated with radiotherapy (relative risk $1.04 ; 95 \%$ confidence interval 0.94 to 1.15 ), but this was not significant. When only deaths due to breast cancer were counted as events the curves were

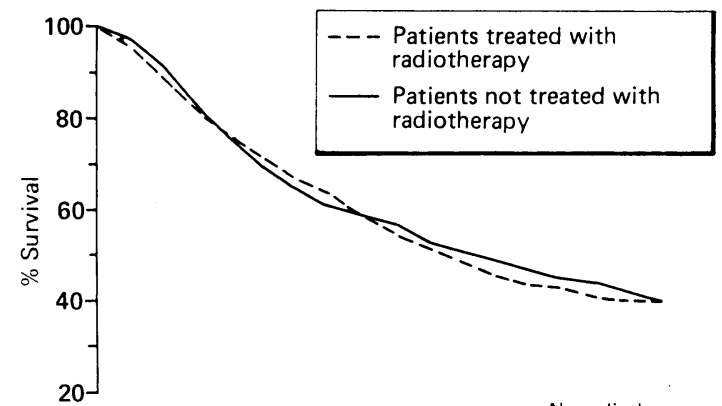

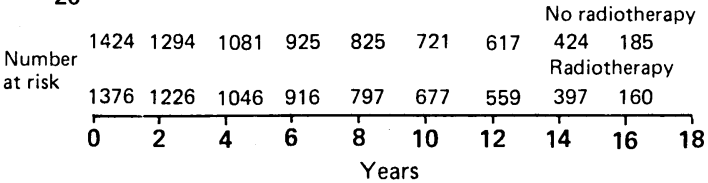

FIG 1-Survival curves for two treatment groups. Number at risk is number of patients alive at entry and every two years thereafter; this decreases in later years as fewer patients had been in trial for relevant length of time $\gamma^{2}=0.57$ (NS)

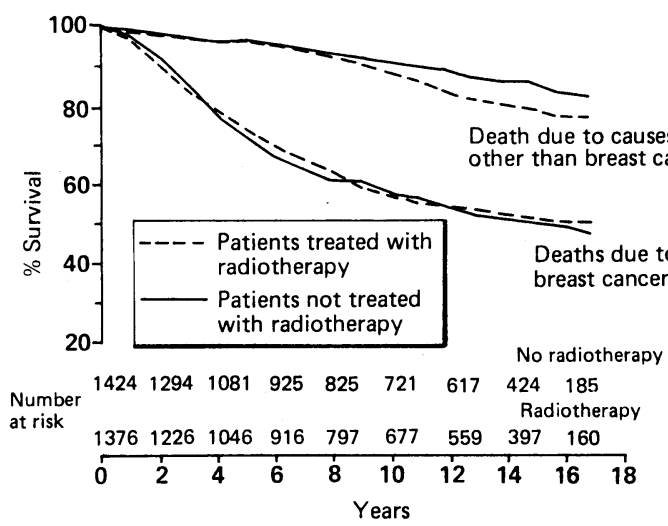

FIG 2-Survival curves according to cause of death. When only deaths from breast cancer were counted as events $\chi^{2}=0 \cdot 28(N S)$; when only deaths from causes other than breast cancer were counted as events $\chi^{2}=7.69, p=0.006$. For definition of numbers at risk see figure 1

TABLE I - Deaths due to causes other than breast cancer in patients who had had breast cancer treated with and without postoperative radiotherapy by affected breast and type of radiation

\begin{tabular}{|c|c|c|c|c|c|}
\hline \multirow{2}{*}{ Type of radiation } & \multirow[b]{2}{*}{ Affected breast } & \multicolumn{2}{|c|}{ Deaths in patients given radiotherapy } & \multirow{2}{*}{$\begin{array}{l}\text { Variance of observed } \\
\text { minus expected }\end{array}$} & \multirow{2}{*}{$\begin{array}{c}\text { Relative risk }^{\star} \\
(95 \% \text { confidence interval })\end{array}$} \\
\hline & & Observed & Expected & & \\
\hline Supervoltage & $\left\{\begin{array}{l}\text { Left } \\
\text { Right }\end{array}\right.$ & $\begin{array}{l}19 \\
29\end{array}$ & $\begin{array}{l}18 \cdot 11 \\
23 \cdot 55\end{array}$ & $\begin{array}{r}9 \cdot 47 \\
12 \cdot 22\end{array}$ & $\begin{array}{l}1 \cdot 10(0.58 \text { to } 2.08) \\
1.56(0.89 \text { to } 2 \cdot 74)\end{array}$ \\
\hline Orthovoltage or mixed & $\left\{\begin{array}{l}\text { Left } \\
\text { Right }\end{array}\right.$ & $\begin{array}{l}66 \\
55\end{array}$ & $\begin{array}{l}49 \cdot 50 \\
54 \cdot 21\end{array}$ & $\begin{array}{l}26 \cdot 74 \\
25: 93\end{array}$ & $\begin{array}{l}1.85(1.27 \text { to } 2.71) \\
1.03(0.70 \text { to } 1.51)\end{array}$ \\
\hline All & $\left\{\begin{array}{l}\text { Left } \\
\text { Right }\end{array}\right.$ & $\begin{array}{l}85 \\
84\end{array}$ & $\begin{array}{l}67 \cdot 61 \\
77 \cdot 76\end{array}$ & $\begin{array}{l}36 \cdot 21 \\
38 \cdot 15\end{array}$ & $\begin{array}{l}1.61(1 \cdot 17 \text { to } 2 \cdot 24) \\
1 \cdot 18(0 \cdot 86 \text { to } 1.62)\end{array}$ \\
\hline All & Either breast & 169 & $145 \cdot 37$ & $74 \cdot 36$ & $1.37(1.09$ to 1.72$)$ \\
\hline
\end{tabular}

${ }^{\star} \log ($ relative risk $)=($ observed-expected $) /$ variance. Relative risk $>1.0$ indicates higher mortality in group given radiotherapy.

Tests for interaction: between left and right overall $\gamma^{2} 1 \cdot 86 ; p=0 \cdot 17$; between left and right in orthovoltage $\chi^{2} 4.53 ; p=0.03$. 
almost superimposed (fig 2) and again the difference was not significant (relative risk $0.97 ; 0.87$ to 1.08 ). When only deaths due to causes other than breast cancer were counted as events (fig 2), however, the curves began to separate in the second quinquennium, and, over the whole period of follow up mortality from these causes was significantly higher in the group treated with radiotherapy (relative risk $1.37 ; 1.09$ to $1 \cdot 72$ ). No significant interactions were detected when the data were divided according to age or stage or size of tumour.

An unexpected finding was that the increase in deaths due to causes other than breast cancer in the group treated with radiotherapy was mainly in patients who had had tumours of the left breast (see table I), in whom the relative risk was $1 \cdot 61(1 \cdot 17$ to $2 \cdot 24)$, though a test for interaction between tumours of the left and right breasts was not significant $(p=0 \cdot 18)$. As noted

TABLE II-Causes of death after five years in patients who had had breast cancer treated with or without postoperative radiotherapy

\begin{tabular}{lcccc}
\hline Cause of death & $\begin{array}{c}\text { Patients given } \\
\text { radiotherapy }\end{array}$ & $\begin{array}{c}\text { Patients not } \\
\text { given radiotherapy }\end{array}$ & Relative risk & $\begin{array}{c}\text { p Value } \\
\text { (logrank comparison) }\end{array}$ \\
\hline Breast cancer & 271 & 278 & $1.02(0.86$ to 1.20$)$ & 0.84 \\
Other malignancies & 37 & 18 & $2 \cdot 11(1.25$ to 3.59$)$ & 0.006 \\
Cardiac related & 46 & 30 & $1.65(1.05$ to 2.58$)$ & 0.03 \\
Other & 44 & 36 & $1.30(0.84$ to $2 \cdot 01)$ & 0.24 \\
Not known & 3 & 2 & & \\
\hline
\end{tabular}

$\star$ See footnote to table I.

treated with orthovoltage was also significant $(p=0 \cdot 03)$.

As the excess deaths in patients with tumours of the left breast may have been due to irradiation of the heart region, and especially as orthovoltage, with its more lateral scatter, gives a higher dose of radiation to this region, we examined in more detail the deaths due to causes other than breast cancer after five years, when

TABLE $\mathrm{V}-$ Deaths from other malignancies after five years in patients who had had breast cancer treated with and without postoperative radiotherapy

\begin{tabular}{lcc}
\hline & $\begin{array}{c}\text { Patients given } \\
\text { radiotherapy }\end{array}$ & $\begin{array}{c}\text { Patients not given } \\
\text { radiotherapy }\end{array}$ \\
\hline Site of cancer: & 4 & 4 \\
$\quad$ Lung & 1 & 2 \\
Stomach & 1 & \\
Jejunum & 1 & 1 \\
Caecum & 6 & 2 \\
Colon-rectum & 4 & 2 \\
Pancreas & 1 & 2 \\
Ovidneys & 6 & 2 \\
Uterus & 2 & \\
$\quad$ Cervix & 3 & 1 \\
Type of malignancy: & 1 & 1 \\
$\quad$ Fibrosarcoma & 1 & \\
$\quad$ Melanoma & 1 & \\
$\quad$ Lymphoma & 1 & \\
Acute myeloblastic leukaemia & 1 & \\
Chronic lymphocytic leukaemia & 1 & \\
\hline Total & 37 & \\
\hline
\end{tabular}

TABLE III - Deaths related to cardiac problems in patients who had had breast cancer treated with or without postoperative radiotherapy at least five years previously by affected breast and type of radiation

\begin{tabular}{|c|c|c|c|c|c|}
\hline \multirow[b]{2}{*}{ Type of radiation } & \multirow[b]{2}{*}{ Affected breast } & \multicolumn{2}{|c|}{ Deaths in patients given radiotherapy } & \multirow{2}{*}{$\begin{array}{l}\text { Variance of observed } \\
\text { minus expected }\end{array}$} & \multirow{2}{*}{$\begin{array}{c}\text { Relative risk } \\
(95 \% \text { confidence interval })\end{array}$} \\
\hline & & Observed & Expected & & \\
\hline Supervoltage & $\left\{\begin{array}{l}\text { Left } \\
\text { Right }\end{array}\right.$ & $\begin{array}{l}5 \\
8\end{array}$ & $\begin{array}{l}4 \cdot 33 \\
7 \cdot 20\end{array}$ & $\begin{array}{l}2 \cdot 25 \\
3 \cdot 74\end{array}$ & $\begin{array}{l}1.35(0.36 \text { to } 4.98) \\
1.24(0.45 \text { to } 3.41)\end{array}$ \\
\hline Orthovoltage or mixed & $\left\{\begin{array}{l}\text { Left } \\
\text { Right }\end{array}\right.$ & $\begin{array}{l}20 \\
13\end{array}$ & $\begin{array}{l}12 \cdot 99 \\
12 \cdot 04\end{array}$ & $\begin{array}{l}7 \cdot 15 \\
5 \cdot 74\end{array}$ & $\begin{array}{l}2.67(1.28 \text { to } 5.55) \\
1.18(0.52 \text { to } 2.67)\end{array}$ \\
\hline All & $\left\{\begin{array}{l}\text { Left } \\
\text { Right }\end{array}\right.$ & $\begin{array}{l}25 \\
21\end{array}$ & $\begin{array}{l}17 \cdot 32 \\
19 \cdot 24\end{array}$ & $\begin{array}{l}9 \cdot 40 \\
9 \cdot 48\end{array}$ & $\begin{array}{l}2 \cdot 26(1 \cdot 19 \text { to } 4 \cdot 29) \\
1 \cdot 20(0.64 \text { to } 2 \cdot 28)\end{array}$ \\
\hline All & Either breast & 46 & $35 \cdot 79$ & $18 \cdot 88$ & $1.65(1.05$ to 2.59$)$ \\
\hline
\end{tabular}

* See footnote to table $I$.

Tests for interaction: between left and right overall $\gamma_{0}^{2} 1 \cdot 88 ; p=0 \cdot 17$; between left and right in orthovoltage $\chi^{2} 2 \cdot 11 ; p=0 \cdot 15$.

above, the earlier trials in which orthovoltage radiation was used contributed most of the data after 10 years in the overview by Cuzick et al. ${ }^{4}$ In the Cancer Research Campaign trial some centres used only supervoltage, others only orthovoltage, and some both. When both were used orthovoltage was almost invariably used for the pectoral fields, supervoltage being used for treatment outside the pectoral area. Table I stratifies deaths due to causes other than breast cancer not only by which breast was affected but also by type of radiation - that is, only supervoltage and only or some orthovoltage. The overall relative risk confirmed the result of the unstratified comparison given above, but two thirds of the excess deaths due to causes other than breast cancer in the group treated with radiotherapy were in patients who had had tumours of the left breast treated by orthovoltage. This, of course, is a finding in a subset and must be viewed with some caution, but the $p$ value was significant $(p=0.0014)$ and a test for interaction between left and right sides in the patients

TABLE IV - Incidence of new malignancies throughout follow up in patients who had had breast cancer treated with or without postoperative radiotherapy

\begin{tabular}{lcccc}
\hline Site & $\begin{array}{c}\text { Patients given } \\
\text { radiotherapy }\end{array}$ & $\begin{array}{c}\text { Patients not } \\
\text { given radiotherapy }\end{array}$ & $\begin{array}{c}\text { Relative risk } \\
\text { (95\% confidence intervals) }\end{array}$ & $\begin{array}{c}\text { p Value } \\
\text { (logrank comparison) }\end{array}$ \\
\hline $\begin{array}{l}\text { Opposite breast } \\
\text { Other }\end{array}$ & 73 & 58 & $1.33(0.97$ to $1 \cdot 88)$ & $0 \cdot 10$ \\
\hline
\end{tabular}

*Sec footnote to table 1 the excess mortality became apparent (fig 2). Table II shows the breakdown by cause of death after five years in the two groups of the trial. More deaths related to cardiac disease and other malignancies were seen in the group treated with radiotherapy. Table III shows the distribution of the deaths related to cardiac disease according to which breast was affected and the type of radiation. The excess deaths in the group treated with radiotherapy occurred mainly in patients with tumours of the left breast whose treatment included orthovoltage radiation (relative risk 2.67; 1.28 to $5 \cdot 55)$, though a test for interaction between tumours of the left and right breasts treated by orthovoltage was not significant $(p=0 \cdot 15)$.

The increased deaths from other malignancies in the patients treated with radiotherapy followed an increased incidence of new malignancies (table IV). There were also more new malignancies in the opposite breast, which were not allowed for in any of the analyses of cause of death as determining whether deaths from breast cancer were due to the first or second primary was impossible. Table $\mathrm{V}$ gives details of the second malignancies responsible for the deaths after five years. The excess in the group treated with radiotherapy was not confined to sites in the upper part of the body where higher radiation doses might have been delivered, nor was it particularly associated with tumours of the left breast or treatment with orthovoltage radiation (table VI). 
TABLE VI - Mortality from other malignancies after five years in patients who had had breast cancer treated with or without postoperative radiotherapy by affected breast and type of radiation

\begin{tabular}{|c|c|c|c|c|}
\hline & \multicolumn{2}{|c|}{ Deaths in patients given radiotherapy } & \multirow{2}{*}{$\begin{array}{l}\text { Variance of observed } \\
\text { minus expected }\end{array}$} & \multirow{2}{*}{$\begin{array}{l}\text { Relative risk } \\
\text { (95\% confidence interval) }\end{array}$} \\
\hline & Observed & Expected & & \\
\hline Affected breast: & & & & \\
\hline Left & 20 & $12 \cdot 99$ & 6.95 & $2 \cdot 74(1.30$ to $5 \cdot 77)$ \\
\hline Right & 17 & $13 \cdot 78$ & $6 \cdot 74$ & $1.61(0.76$ to 3.43$)$ \\
\hline \multicolumn{5}{|l|}{ Type of radiation: } \\
\hline Supervoltage & 9 & $6 \cdot 22$ & $3 \cdot 24$ & $2.35(0.79$ to 7.00$)$ \\
\hline Orthovoltage & 28 & $20 \cdot 58$ & $10 \cdot 49$ & $2 \cdot 03(1.11$ to 3.72$)$ \\
\hline All patients & 37 & $26 \cdot 72$ & $13 \cdot 73$ & $2 \cdot 20(1.29$ to $3 \cdot 73)$ \\
\hline
\end{tabular}

* See footnote to table I.

Tests for interaction: between left and right $\chi^{2} 0.96 ; p=0.33$; between orthovoltage and supervoltage $\chi^{2} 0.06 ; p=$ 0.81 .

\section{Discussion}

This analysis of the Cancer Research Campaign (King's/Cambridge) trial confirms that late mortality was significantly increased in patients treated with radiotherapy, as reported by Cuzick $e t a l^{4}$; this was due to an excess of deaths from causes other than breast cancer, which was significant even when the analysis was made over the whole follow up. More detailed examination of the causes of the excess mortality showed that there was an increased risk of death from other cancers and cardiac disease.

These findings lend some support to the suggestion that radiotherapy may adversely affect the immune system. ${ }^{3}$ In previous studies of the excess risk of cancer associated with radiotherapy the malignancies were predominantly in or close to the parts of the body that received the highest radiation. Thus, for example, patients irradiated for ankylosing spondylitis or an artificial menopause showed the excess of malignancies after long follow up predominantly in the heavily irradiated sites. ${ }^{7-9}$ The fact that the excess malignancies in our study were not predominantly in or close to the parts of the body that would have received the highest dose of radiation, however, might indicate that the long term adverse systemic effect is mediated by irradiation of the lymphocytes recirculating in the thoracic duct. Our results are also at variance with those of Jones and Ribeiro, who did not find a significant excess of deaths from other cancers in the patients treated with radiotherapy in trials in Manchester in 1949-55. ${ }^{10}$

The other main contribution to the excess mortality in the group treated with radiotherapy was from deaths related to cardiac disease in patients who had had tumours of the left breast (table III). This would be consistent with radiation damaging the heart and its associated structures. Irradiation of the heart would arise mainly from the tangential pectoral fields used in the usual postoperative technique, and because of increased sideways scatter the dose would be higher with orthovoltage than with supervoltage radiation. The fact that the excess mortality seems to have been mainly in patients who had had tumours of the left breast treated by orthovoltage radiation supports this hypothesis. Caution is needed, however, in interpreting these analyses of subgroups and the hypotheses derived from the data: the observation concerning orthovoltage radiotherapy (which was not a randomised option) may be a statistical artefact. Nevertheless, the same tendency for more deaths due to cardiac disease in patients who had had tumours of the left breast was reported in the Manchester trials, in which orthovoltage was used, though a test for interaction between tumours of the left and right breasts was not significant. ${ }^{10}$
What are the implications of our results for the current use of adjuvant radiotherapy to treat early breast cancer? As always, the harmful effects of treatment have to be weighed against its benefits. Radiotherapy reduces the risk of local recurrence and the consequent distress this may cause a patient due to uncontrolled local disease at the time of death. ${ }^{11}$ It may also be considered an essential part of any treatment aimed at conserving the breast, an option that many patients consider highly desirable. On the debit side are the immediate trauma and inconvenience caused by radiotherapy, and to these must now be added the increased risk of death after long follow up.

The risk of death, however, must be put in perspective. The number of excess deaths is small in relation to the total number of patients treated. In the total follow up period (to 1988) of the Cancer Research Campaign trial 56.9\% (783/1376) of the irradiated group died, compared with $55 \cdot 5 \%(791 / 1424)$ of the group allocated to a watch policy. Cuzick et al in their overview reported for all follow up a mortality of $52.6 \%$ (2071/ 3935 ) in those given radiotherapy compared with $51 \cdot 8 \%(2077 / 4006)$ in those not given radiotherapy. The risk-benefit analysis, therefore, has to be assessed for each patient individually, but on present evidence we think that for many patients radiotherapy is still a desirable part of their initial treatment. In undertaking such treatment radiotherapists should try particularly to minimise the dose to the cardiac region.

Finally, those patients at the highest risk of local recurrence-for example, those with large, poorly differentiated primary cancers with affected axillary nodes - for whom postoperative radiotherapy is most justified are the ones likely to die of breast cancer within 10 years and therefore less likely to experience the delayed toxic effects of this treatment. In contrast, those women with small breast cancers, perhaps detected by mammography, have an excellent chance of living beyond 10 years and would then be at greatest hazard of developing the long term unwanted effects of radical radiotherapy. For this reason the need for postoperative radiotherapy in patients treated conservatively is being assessed with other forms of adjuvant treatment in randomised controlled trials organised by the Cancer Research Campaign group.

We thank all who took part in this trial; Mrs J Reeley for typing the manuscript; and the Cancer Research Campaign for the continued financial support.

1 Easson EC. Post-operative radiotherapy in breast cancer. In: Forrest APM Kunkler PH, eds. Prognostic factors in breast cancer. Edinburgh: Churchill Livingstone, 1968:118-27.

2 Cancer Research Campaign Working Party. Cancer Research Campaign (King's/Cambridge) trial for early breast cancer: a detailed update of the tenth year. Lancet 1980;ii:55-60.

3 Stjensward J. Decreased survival related to irradiation postoperatively in early operable breast cancer. Lancet 1974; ii:1285-6.

4 Cuzick J, Stewart H, Peto R, et al. Overview of randomized trials of postoperative adjuvant radiotherapy in breast cancer. Cancer Treat Rep 1987;71:15-29.

5 Brinkley D, Haybittle JL, Houghton J. The Cancer Research Campaign (King's/Cambridge) trial for early breast cancer: an analysis of the radiotherapy data. Br f Radiol 1984;57:309-16.

6 Peto R, Peto J. Asymptotically efficient rank invariant test procedures. foumal of the Royal Statistical Society Series $A$ 1972;135:185-98.

7 Court Brown WM, Doll R. Mortality from cancer and other causes after radiotherapy for ankylosing spondilitis. $\mathrm{Br} \mathrm{Med} \mathcal{F} 1965$;ii: $1327-32$.

8 Brinkley D, Haybittle JL. The late effects of artificial menopause by $\mathrm{X}$ radiation. Brf Radiol 1969;42:519-21.

9 Smith PG, Doll R. Late effects of X-irradiation in patients treated for metropathia menorrhagia. Brf Radiol 1976;49:224-32.

10 Jones JM, Ribeiro GG. Mortality patterns over 34 years of breast cancer patients in a clinical trial of post-operative radiotherapy. Clin Radio 1989;40:204-8.

11 Berstock DJ, Houghton J, Haybittle JL, Baum $M$. The role of radiotherapy following total mastectomy for patients with early breast cancer. World $\mathcal{f}$ Surg 1980;9:667-70

(Accepted 10 April 1989) 